\title{
Plasma Amino Acid Concentrations at Birth and Patent Ductus Arteriosus in Very and Extremely Preterm Infants
}

\author{
Maurice J. Huizing ${ }^{1}$, Moreyba Borges-Luján ${ }^{2}$, Giacomo Cavallaro ${ }^{3}$, \\ Gema E. González-Luis ${ }^{2}$, Genny Raffaeli ${ }^{3,4}$, Pilar Bas-Suárez ${ }^{5}$, Jaap A. Bakker ${ }^{6}$, \\ Rob M. Moonen ${ }^{7}$ and Eduardo Villamor ${ }^{1 *}$
}

${ }^{1}$ Department of Pediatrics, Maastricht University Medical Centre (MUMC+), School for Oncology and Developmental Biology (GROW), Maastricht, Netherlands, ${ }^{2}$ Department of Neonatology, Complejo Hospitalario Universitario Insular Materno-Infantil (CHUIMI) de Canarias, Las Palmas de Gran Canaria, Spain, ${ }^{3}$ Neonatal Intensive Care Unit, Fondazione IRCCS Cà Granda Ospedale Maggiore Policlinico, Milan, Italy, ${ }^{4}$ Department of Clinical Sciences and Community Health, Università degli Studi di Milano, Milan, Italy, ${ }^{5}$ Department of Pediatrics, Hospital Vithas Santa Catalina, Las Palmas de Gran Canaria, Spain, ${ }^{6}$ Department of Clinical Chemistry and Laboratory Medicine, Leiden University Medical Center, Leiden, Netherlands,

${ }^{7}$ Department of Pediatrics, Zuyderland Medical Center, Heerlen, Netherlands

OPEN ACCESS

Edited by:

Ömer Erdeve,

Ankara University, Turkey

Reviewed by:

Fuat Emre Canpolat,

Ministry of Health (Turkey), Turkey

Tulin Gokmen Yildirim,

University of Health Sciences

(Turkey), Turkey

${ }^{*}$ Correspondence:

Eduardo Villamor

e.villamor@mumc.nı

Specialty section: This article was submitted to

Neonatology,

a section of the journal

Frontiers in Pediatrics

Received: 28 December 2020 Accepted: 20 January 2021

Published: 11 February 2021

Citation:

Huizing MJ, Borges-Luján M,

Cavallaro G, González-Luis GE, Raffaeli G, Bas-Suárez P, Bakker JA, Moonen RM and Villamor E (2021) Plasma Amino Acid Concentrations at Birth and Patent Ductus Arteriosus in Very and Extremely Preterm Infants.

Front. Pediatr. 9:647018.

doi: $10.3389 /$ fped.2021.647018
Background: Amino acids are increasingly recognized as bioactive molecules in numerous physiological and pathophysiological pathways. The non-essential amino acid glutamate is vasoactive in the rat ductus arteriosus (DA) and a decrease in its levels within the 1 st days of life has been associated with the presence of patent DA (PDA) in extremely preterm infants. However, these findings have not been confirmed in other studies.

Objective: To investigate the possible association between amino acid concentrations in the 1st day of life and the presence of PDA in a cohort of 121 newborns with gestational age (GA) below 30 weeks and birth weight (BW) below 1,500 g.

Methods: Plasma samples were collected 6-12h after birth and amino acid concentrations were determined by tandem mass spectrometry. Besides PDA, we analyzed the potential association of amino acid concentrations with infant sex, small for GA (SGA, defined as BW<third percentile), antenatal corticosteroids, chorioamnionitis, and preeclampsia. Group differences were analyzed by ANOVA adjusted for GA and BW. A Bonferroni significance threshold of $P<0.0024$ was used to correct for multiple testing.

Results: PDA was found in 48 of the 121 infants examined. We observed higher mean levels of glutamate in infants with PDA (147.0 $\mu \mathrm{mol} / \mathrm{L}, \mathrm{SD}$ 84.0) as compared with those without (106.7 $\mu \mathrm{mol} / \mathrm{L}, \mathrm{SD} 49.1, P=0.0006)$. None of the other amino acid concentrations in the PDA group reached the level of statistical significance that was pre-set to correct for multiple comparisons. Glutamate levels were not significantly affected by infant sex, being SGA, or by exposure to antenatal corticosteroids, clinical chorioamnionitis, or preeclampsia.

Conclusion: Our study not only does not confirm the previous findings of low glutamate levels in preterm infants with PDA, but we have even found elevated glutamate concentrations associated with PDA. Nevertheless, despite the high statistical significance, the difference in glutamate levels may lack clinical significance or may be an epiphenomenon associated with the particular clinical condition of infants with PDA.

Keywords: amino acids, ductus arteriosus [MeSH], glutamate, preterm (birth), metabolomic analysis 


\section{INTRODUCTION}

Failed or delayed closure of the ductus arteriosus (DA) after birth leads to patent DA (PDA), a common condition among very preterm infants (1-6). The two most relevant vasoactive factors that maintain the DA open during fetal life and mediate its closure after birth are oxygen tension and prostaglandins $(4,5)$. However, the DA responds to numerous vasoactive agents and its closure is finally the result of a complex interaction of mediators and pathways $(4,5)$.

In a recent study, Fujita et al. proposed a role for the nonessential amino acid glutamate in the postnatal closure of the DA (7). They reported that plasma glutamate concentration was significantly lower in extremely preterm infants (gestational age $<28$ weeks) with PDA compared to those without the condition (7). In addition, they observed that intraperitoneal injection of glutamate to pregnant rats induced ductal contraction in the fetus. Moreover, they showed that the mRNA of the glutamate ionotropic receptor $\alpha$-amino-3-hydroxy-5-methyl4-isoxazolepropionate (AMPA) type subunit one was highly expressed in rat DA compared to the aorta, and was co-localized with autonomic nerve terminals in the human and rat DA. In agreement with these results, microarrays comparing the genetic profiles of the DA and ascending aorta from mice and rats showed significant changes in the ductal expression of both ionotropic and metabotropic glutamate receptors $(8,9)$. Altogether, these data suggest a role for glutamatergic signaling in the physiology and/or pathobiology of the DA. Nevertheless, more studies are needed to confirm this hypothesis.

Between 2007 and 2012, our group conducted a prospective study to analyze the association between polymorphisms of the carbamoyl phosphate synthetase (CPS) gene and necrotizing enterocolitis (NEC) (10-12). In that research, plasma levels of amino acids were determined in the 1st day of life in order to correlate them with the primary outcome of the study. One of the secondary outcomes of the study was PDA. Our aim was to use these unpublished data to investigate the association between glutamate, as well as other amino acids, and the presence of PDA in infants with a gestational age (GA) below 30 weeks.

\section{METHODS}

\section{Study Population}

This study was performed in a previously described cohort of 121 preterm infants (GA $\leq 30$ weeks and birth weight $\leq 1,500 \mathrm{~g}$ ) admitted to the level III neonatal intensive care units of the Maastricht University Medical Center (Maastricht, The Netherlands), Hospital Universitario Materno-Infantil de Canarias (Las Palmas de Gran Canaria, Spain), and Carlo Poma Hospital (Mantova, Italy) between July 2007 and October 2008. All infants had been enrolled in the study "Carbamoyl Phosphate Synthetase (CPS) Polymorphisms as Risk Factor for NEC" (NCT00554866). The institutional review board (IRB) of the three participating centers approved the use of the clinical data of the patients for the present study (IRB numbers: Maastricht MEC-07-2-018; Las Palmas CEIC- 276; Mantova 21366/2007). Written informed consent was obtained from the parents for inclusion in the study. Infants exposed to a blood transfusion, enteral or parenteral proteins/amino acids, or inhaled NO before blood sampling were excluded from the study. The correlation between arginine, citrulline and dimethylarginine levels and CPS polymorphisms and NEC in the same group of patients has been the subject of another publications of our group $(10,11)$.

\section{PDA Assessment and Other Clinical Variables}

The perinatal and neonatal data of enrolled infants (Table 1) were extracted from the database of the NCT00554866 trial. At the time of inclusion of the children in the cohort (2007-2008), the three participating centers had very similar protocols for detection and treatment of PDA. These protocols included the performance of a screening echocardiogram by a pediatric cardiologist on postnatal day 2 to 5 . As previously described, hemodynamically significant PDA was defined by a transductal diameter $>1.5 \mathrm{~mm}$ with unrestrictive $(<1 \mathrm{~m} / \mathrm{s})$ left to right transductal flow on pulse wave Doppler and clinical signs of pulmonary overcirculation (e.g., increasing ventilation, oxygenation problems) and/or systemic hypoperfusion (e.g., abdominal distension, oliguria) (13). In the absence of clear clinical signs, ascertainment of hemodynamic significance was made on the basis of any of the following echocardiographic characteristics: left atrial/aortic root ratio $>1.4$, mean velocity in the left pulmonary artery $>0.6 \mathrm{~m} / \mathrm{s}$, or diastolic backflow in the abdominal aorta (13).

GA was determined by the last menstrual period and early ultrasounds (before 20 weeks of gestation). Besides the presence of PDA, the following demographic and clinical characteristics were collected and correlated with the amino acid concentrations: infant sex; small for GA (SGA, defined as birth weight for GA below the sex-specific third percentile); antenatal corticosteroids (defined as two doses of betamethasone administered $24 \mathrm{~h}$ apart); clinical chorioamnionitis (defined as every clinical suspicion of infection of the chorion, amnion, amniotic fluid, placenta, or a combination as judged by the obstetrician); and preeclampsia (based on the obstetrician's diagnosis).

\section{Plasma Amino Acid Analysis}

One blood sample $(500 \mu \mathrm{L})$ was obtained between 6 and $12 \mathrm{~h}$ after birth from an umbilical artery or peripheral artery catheter. When not available, the blood sample was obtained from venous puncture. Immediately after collection, heparinized blood samples were put on ice and centrifuged within $10 \mathrm{~min}$ $\left(4,000 \mathrm{rpm}, 10 \mathrm{~min}, 4^{\circ} \mathrm{C}\right)$ to obtain plasma. The plasma was deproteinized with $6 \mathrm{mg}$ of solid 5-sulfosalicylic acid (SSA; Sigma, St. Louis, MO, USA) per $100 \mu \mathrm{L}$ plasma, and stored at $-80^{\circ} \mathrm{C}$ until further analysis. The samples obtained in Las Palmas and Mantova were transported on dry ice to Maastricht where all the analyses were performed (10).

Concentrations of (underivatized) amino acids in plasma were determined using an ultra-performance liquid chromatography (UPLC) separation module coupled to an electrospray ionization tandem mass spectrometry (ESI-MS/MS, Quattro Premier, Waters, Etten-Leur, The Netherlands). Stable isotope labeled 
TABLE 1 | Baseline characteristics and neonatal complications in preterm infants with and without PDA.

\begin{tabular}{|c|c|c|c|c|c|}
\hline & $\begin{array}{l}\text { PDA-yes } \\
(n=48)\end{array}$ & $\begin{array}{l}n \text { data } \\
\text { missing }\end{array}$ & $\begin{array}{l}\text { PDA-no } \\
(n=73)\end{array}$ & $\begin{array}{l}n \text { data } \\
\text { missing }\end{array}$ & $\begin{array}{c}P \text { - } \\
\text { value }\end{array}$ \\
\hline Birth weight (g) & 967 (SD 238) & 0 & $\begin{array}{c}1,069 \text { (SD } \\
238)\end{array}$ & 0 & 0.023 \\
\hline $\begin{array}{l}\text { Gestational age } \\
\text { (wks) }\end{array}$ & 27.5 (SD 1.5) & 0 & 28.6 (SD 1.5) & 0 & 0.000 \\
\hline Male sex & $26(54.2)$ & 0 & 43 (58.9) & 0 & 0.607 \\
\hline Prenatal steroids & $39(81.2)$ & 0 & 55 (77.5) & 2 & 0.159 \\
\hline Preeclampsia & 5 (10.6) & 1 & $20(28.2)$ & 2 & 0.023 \\
\hline $\begin{array}{l}\text { Clinical } \\
\text { chorioamnionitis }\end{array}$ & $2(4.2)$ & 0 & $9(12.3)$ & 0 & 0.127 \\
\hline Vaginal delivery & 16 (33.3) & 0 & $24(32.9)$ & 0 & 0.958 \\
\hline Apgar (1 min) & $5(4-7)$ & 1 & $7(5-8)$ & 0 & 0.079 \\
\hline Apgar (5 min) & $8(6-9)$ & 1 & $9(7-9)$ & 0 & 0.109 \\
\hline RDS & $36(75.0)$ & 0 & $40(55.6)$ & 1 & 0.030 \\
\hline Mechanical vent. & 15 (83.3) & 0 & 40 (56.3) & 2 & 0.002 \\
\hline BPD & $19(45.2)$ & 6 & $14(21.2)$ & 7 & 0.008 \\
\hline Hypotension & $26(54.2)$ & 0 & 27 (37.5) & 1 & 0.072 \\
\hline Sepsis & $29(63.0)$ & 2 & 34 (46.6) & 0 & 0.080 \\
\hline NEC & $5(10.9)$ & 2 & $2(2.9)$ & 5 & 0.084 \\
\hline $\mathrm{IVH}$ & $18(37.5)$ & 0 & 17 (23.6) & 1 & 0.101 \\
\hline PVL & 5 (10.4) & 0 & $4(5.5)$ & 0 & 0.311 \\
\hline $\mathrm{ROP}$ & $4(10.0)$ & 8 & $5(7.5)$ & 6 & 0.647 \\
\hline Mortality & 7 (14.6) & 0 & 9 (12.3) & 0 & 0.720 \\
\hline
\end{tabular}

Results are expressed as mean (SD). median [interquartile range] or absolute numbers of patients (percentage). PDA, patent ductus arteriosus; RDS, respiratory distress syndrome; $B P D$, bronchopulmonary dysplasia (defined as oxygen at 36 weeks postmenstrual age); $N E C$, necrotizing enterocolitis ( $\geq$ stage II); $I V H$, intraventricular hemorrhage ( $\geq$ grade 2); $P V L$, periventricular leukomalacia; $R O P$, retinopathy of prematurity ( $\geq$ stage II).

amino acids were used as internal standards for quantification of plasma amino acids. All analyses were performed in one laboratory (Department of Clinical Genetics, Maastricht University Medical Center, Maastricht, The Netherlands) (10).

\section{Statistical Analysis}

Results for continuous variables are expressed as mean (SD) or, if variables were not normally distributed, as median (interquartile range). Standardized residuals were examined for outliers, and measurements that were $<-3.0$ or $>3.0 \mathrm{SD}$ from the mean were removed. The possible relationship between amino acid concentrations and PDA was evaluated by ANOVA with adjustment for gestational age, and birth weight. Analysis included 21 ANOVA models (one clinical variable $\times 21$ amino acid measurements) and a Bonferonni significance threshold of $P$ $<0.0024$ ( 0.05 divided by 21) was used to correct for multiple testing (14). We performed a power analysis to determine the minimum amino acid concentration ratio (PDA-yes:PDA-no) that would be reach statistical significance $(P<0.0024)$ with our sample size (15). The results of the power analysis are shown in Supplementary Table 1 . All analyses were performed using IBM SPSS Statistics for Windows (Version 22.0; Armonk, NY, USA).

\section{RESULTS}

PDA was found in 48 of the 121 infants examined. The characteristics of the cohort are summarized in Table 1. The plasma concentrations of the different amino acids and their relation to PDA are shown in Table 2. Glutamate was the only amino acid whose concentration was significantly different $(P<$ $0.0006)$ when the groups with and without PDA were compared. None of the clinical or perinatal characteristics, including sex, BW below third percentile, use of antenatal corticosteroids, history of chorioamnionitis, or history of preeclampsia, led to significant differences in glutamate concentrations (Table 3). Glutamate concentrations were also not significantly different in infants who developed intraventricular hemorrhage ( $\geq$ grade 2), NEC ( $\geq$ stage II), bronchopulmonary dysplasia (defined as supplementary oxygen at 36 weeks postmenstrual age), or retinopathy of prematurity ( $\geq$ stage II) (Table 3 ).

Changes in amino acid concentrations depending on infant sex, SGA, and exposure to antenatal corticosteroids, chorioamnionitis, or preeclampsia are depicted in Supplementary Tables 2-6. SGA infants showed increased plasma concentrations of asparagine, glutamine, glycine and alanine (Supplementary Table 3). Tryptophan levels were significantly reduced in infants exposed to preeclampsia (Supplementary Table 5) and $\alpha$-aminobutyric acid levels were significantly increased in infants exposed to antenatal corticosteroids (Supplementary Table 6).

\section{DISCUSSION}

Along with their fundamental role as elements for protein and peptide synthesis, amino acids are increasingly recognized as bioactive molecules in numerous physiological and pathophysiological pathways (16). Alterations in amino acid levels during the 1st days of postnatal life have been associated with clinical conditions of prematurity such as RDS or NEC (10, 17-20). Closure of the DA at birth is one of the processes in which a participation of amino acids, specifically glutamate, has been proposed. However, data supporting this potential role of glutamate, although provocative, are still scarce (7). In the present study, we analyzed the concentrations of amino acids in plasma samples obtained between 6 and $12 \mathrm{~h}$ of life in a group of preterm newborns who had not yet received amino acid supplementation. Interestingly, glutamate was the only amino acid whose concentration was significantly different between the groups with and without PDA. However, in contrast to the previous report by Fujita et al. (7), glutamate levels were higher in the PDA group. None of the other amino acids showed differences in plasma concentrations in the PDA group that reached the level of statistical significance $(P<$ 0.0024 ) preset in our analysis. In addition, neither infant sex nor obstetric or perinatal conditions significantly affected glutamate concentrations.

Glutamate is a pleiotropic molecule acting at the crossroads of metabolism and signaling, and functioning as both substrate and product in many distinct physiological processes (21-24). Glutamate is synthesized from glutamine, $\alpha$-ketoglutarate and 
TABLE 2 | Plasma concentrations of amino acids ( $\mu \mathrm{mol} / L$ ) in preterm infants with and without PDA.

\begin{tabular}{|c|c|c|c|c|c|c|}
\hline Amino acid & PDA status & Mean & SD & $N$ & $P$-value & $\begin{array}{l}\text { Adjusted } \\
P \text {-value }\end{array}$ \\
\hline \multirow[t]{2}{*}{ Glutamate } & PDA-no & 106.7 & 49.1 & 66 & 0.004 & 0.0006 \\
\hline & PDA-yes & 147.0 & 84.0 & 47 & & \\
\hline \multirow[t]{2}{*}{ Asparagine } & PDA-no & 60.8 & 22.6 & 70 & 0.870 & 0.636 \\
\hline & PDA-yes & 61.5 & 25.6 & 47 & & \\
\hline \multirow[t]{2}{*}{ Serine } & PDA-no & 155.8 & 45.3 & 71 & 0.232 & 0.092 \\
\hline & PDA-yes & 168.4 & 61.9 & 48 & & \\
\hline \multirow[t]{2}{*}{ Glutamine } & PDA-no & 481.1 & 189.9 & 69 & 0.189 & 0.692 \\
\hline & PDA-yes & 441.2 & 176.1 & 44 & & \\
\hline \multirow[t]{2}{*}{ Histidine } & PDA-no & 72.7 & 19.6 & 70 & 0.311 & 0.163 \\
\hline & PDA-yes & 76.8 & 23.8 & 45 & & \\
\hline \multirow[t]{2}{*}{ Glycine } & PDA-no & 313.9 & 117.2 & 72 & 0.614 & 0.167 \\
\hline & PDA-yes & 325.5 & 129.1 & 47 & & \\
\hline \multirow[t]{2}{*}{ Threonine } & PDA-no & 247.4 & 90.3 & 72 & 0.257 & 0.039 \\
\hline & PDA-yes & 268.1 & 105.5 & 47 & & \\
\hline \multirow[t]{2}{*}{ Citrulline } & PDA-no & 21.3 & 6.3 & 68 & 0.894 & 0.807 \\
\hline & PDA-yes & 21.2 & 5.5 & 48 & & \\
\hline \multirow[t]{2}{*}{ Arginine } & PDA-no & 45.2 & 22.5 & 73 & 0.026 & 0.074 \\
\hline & PDA-yes & 35.7 & 21.9 & 45 & & \\
\hline \multirow[t]{2}{*}{ Alanine } & PDA-no & 329.8 & 178.0 & 69 & 0.718 & 0.441 \\
\hline & PDA-yes & 342.2 & 181.5 & 45 & & \\
\hline \multirow[t]{2}{*}{ Taurine } & PDA-no & 208.0 & 94.0 & 73 & 0.664 & 0.468 \\
\hline & PDA-yes & 200.9 & 75.6 & 47 & & \\
\hline \multirow{2}{*}{$\begin{array}{l}\alpha- \\
\text { aminobutyric } \\
\text { acid }\end{array}$} & PDA-no & 15.9 & 7.6 & 72 & 0.204 & 0.253 \\
\hline & PDA-yes & 18.1 & 10.0 & 48 & & \\
\hline \multirow[t]{2}{*}{ Tyrosine } & PDA-no & 109.8 & 31.5 & 69 & 0.015 & 0.027 \\
\hline & PDA-yes & 129.7 & 48.8 & 48 & & \\
\hline \multirow[t]{2}{*}{ Valine } & PDA-no & 167.1 & 49.3 & 67 & 0.201 & 0.216 \\
\hline & PDA-yes & 182.8 & 52.0 & 45 & & \\
\hline \multirow[t]{2}{*}{ Methionine } & PDA-no & 49.0 & 28.0 & 71 & 0.004 & 0.023 \\
\hline & PDA-yes & 66.8 & 37.6 & 48 & & \\
\hline \multirow[t]{2}{*}{ Isoleucine } & PDA-no & 50.2 & 24.5 & 70 & 0.953 & 0.831 \\
\hline & PDA-yes & 49.9 & 25.2 & 46 & & \\
\hline \multirow[t]{2}{*}{ Phenylalanine } & PDA-no & 68.8 & 15.1 & 70 & 0.606 & 0.358 \\
\hline & PDA-yes & 70.7 & 21.2 & 46 & & \\
\hline \multirow[t]{2}{*}{ Tryptophan } & PDA-no & 27.7 & 8.2 & 66 & 0.204 & 0.014 \\
\hline & PDA-yes & 29.7 & 7.7 & 46 & & \\
\hline \multirow[t]{2}{*}{ Leucine } & PDA-no & 69.1 & 22.7 & 67 & 0.578 & 0.432 \\
\hline & PDA-yes & 71.8 & 27.5 & 44 & & \\
\hline \multirow[t]{2}{*}{ Ornithine } & PDA-no & 80.7 & 40.7 & 71 & 0.062 & 0.033 \\
\hline & PDA-yes & 95.9 & 45.9 & 47 & & \\
\hline \multirow[t]{2}{*}{ Lysine } & PDA-no & 261.1 & 103.6 & 72 & 0.510 & 0.423 \\
\hline & PDA-yes & 274.3 & 108.6 & 46 & & \\
\hline
\end{tabular}

Results are expressed as mean (SD). Standardized residuals were examined for outliers, and measurements that were $<-3.0$ or $>3.0$ SD from the mean were removed. Adjusted for gestational age and birth weight. PDA, patent ductus arteriosus.

5-oxoproline and in turn is the precursor for the biosynthesis of amino acids such as L-proline and L-arginine (24). In addition, other neurotransmitters as well as the antioxidant glutathione are
TABLE 3 | Plasma concentrations of glutamate ( $\mu \mathrm{mol} / \mathrm{L})$ in different characteristics and outcomes of preterm infants.

\begin{tabular}{|c|c|c|c|c|c|}
\hline $\begin{array}{l}\text { Characteristic/ } \\
\text { outcome }\end{array}$ & Mean & SD & $N$ & $P$-value & $\begin{array}{c}\text { Adjusted } \\
P \text {-value }\end{array}$ \\
\hline Female & 150.3 & 85.4 & 52 & 0.012 & 0.019 \\
\hline Male & 115.3 & 57.4 & 70 & & \\
\hline SGA-no & 128.2 & 74.1 & 101 & 0.523 & 0.857 \\
\hline SGA-yes & 132.3 & 59.3 & 22 & & \\
\hline $\begin{array}{l}\text { Prenatal } \\
\text { steroids-no }\end{array}$ & 120.0 & 79.6 & 25 & 0.574 & 0.302 \\
\hline $\begin{array}{l}\text { Prenatal } \\
\text { steroids-yes }\end{array}$ & 130.5 & 70.5 & 95 & & \\
\hline $\begin{array}{l}\text { Preeclampsia- } \\
\text { no }\end{array}$ & 126.6 & 73.7 & 91 & 0.687 & 0.162 \\
\hline $\begin{array}{l}\text { Preeclampsia- } \\
\text { yes }\end{array}$ & 116.6 & 45.2 & 23 & & \\
\hline $\begin{array}{l}\text { Chorioamnionitis- } \\
\text { no }\end{array}$ & 137.1 & 72.5 & 111 & 0.007 & 0.015 \\
\hline $\begin{array}{l}\text { Chorioamnionitis- } \\
\text { yes }\end{array}$ & 77.6 & 56.3 & 12 & & \\
\hline BPD-no & 124.4 & 76.6 & 74 & 0.742 & 0.160 \\
\hline BPD-yes & 128.5 & 49.7 & 31 & & \\
\hline NEC-no & 129.3 & 70.7 & 105 & 0.196 & 0.224 \\
\hline NEC-yes & 166.4 & 106.6 & 7 & & \\
\hline IVH-no & 139.4 & 82.8 & 85 & 0.200 & 0.470 \\
\hline IVH-yes & 122.3 & 57.5 & 35 & & \\
\hline ROP-no & 122.1 & 63.6 & 93 & 0.157 & 0.066 \\
\hline ROP-yes & 71.3 & 32.9 & 7 & & \\
\hline
\end{tabular}

Results are expressed as mean (SD). Standardized residuals were examined for outliers, and measurements that were $<-3.0$ or $>3.0 S D$ from the mean were removed. Adjusted for gestational age and birth weight. SGA, small for gestational age; BPD, bronchopulmonary dysplasia (defined as oxygen at 36 weeks postmenstrual age); NEC, necrotizing enterocolitis ( $\geq$ stage II); $I N H$, intraventricular hemorrhage ( $\geq$ grade 2); $R O P$, retinopathy of prematurity ( $\geq$ stage II).

also synthesized from glutamate (24). This ubiquity of glutamate and its metabolism greatly complicates the interpretation of our results. Although we have found an association between high levels of glutamate at birth and the presence of PDA, glutamate levels may be reflecting some other aspect of the perinatal clinical condition rather than having a direct effect on DA closure. Many of the maternal pathological conditions that result in preterm birth are accompanied by alterations in the aminogram that can be transferred to the fetus and affect plasma amino acid levels in the 1 st $\mathrm{h}$ of life (25-27). However, as mentioned above, we did not find significant changes in glutamate in SGA infants or after exposure to clinical chorioamnionitis, preeclampsia, or antenatal steroids. In addition, infection and brain injury, two conditions that are very frequently present among very preterm infants, are known to alter the circulating levels of glutamate and other amino acids $(28,29)$.

Glutamate receptors are divided into the ligand-gated ion channel receptors (ionotropic receptors) and $\mathrm{G}$ protein-coupled metabotropic receptors (30). Ionotropic receptors are further classified into three groups based on their pharmacology and 
structural properties: $N$-methyl-D-aspartate (NMDA), AMPA and kainate receptors (30). Glutamatergic communication through NMDA receptors is key in the central nervous system where glutamate is the main excitatory neurotransmitter (21, 22). However, glutamatergic signaling may also occur in nonneuronal tissues, including the cardiovascular system (30-42).

Little is known about glutamate signaling in the vascular system even though not only endothelial and smooth muscle cells can release glutamate, but also platelets and immune cells $(21,34,43)$. The vascular effects of glutamate may vary depending on the vascular bed studied. Because of its important role in nervous system homeostasis, most studies have focused on brain (micro)circulation where glutamate is a vasodilator. Nitric oxide (39), carbon monoxide $(30,40,41)$, and prostaglandins (42) have been involved in glutamate-induced vasodilation in the central nervous system. As regards other vascular territories, Nguyen-Duong showed glutamate-induced relaxation in porcine coronary arteries (33). This relaxation was attenuated by 4aminopyridine which suggests the involvement of voltage-gated $\mathrm{K}^{+}\left(\mathrm{K}_{\mathrm{V}}\right)$ channels. Inhibition of $\mathrm{K}_{\mathrm{V}}$ channels by reactive oxygen species is one of the main mechanisms responsible for oxygeninduced contraction of the DA $(4,5) . K_{V}$ channel inhibition leads to membrane depolarization and increased $\mathrm{Ca}^{2+}$ entry through L-type $\mathrm{Ca}^{2+}$ channels $(4,5)$. Interestingly, Dumas et al. have recently reported $\mathrm{K}_{\mathrm{V}}$-mediated, $\mathrm{Ca}^{2+}$-dependent glutamate release from human pulmonary arterial smooth muscle cells (21). Finally, as mentioned elsewhere, Fujita et al. showed glutamateinduced contraction of fetal rat DA and proposed an AMPA receptor-mediated release of noradrenaline as the mechanism underlying this contraction (7). Another interesting vascular effect of glutamate with potential impact on DA biology is its role as platelet activator, which is in part cyclooxygenase-dependent $(34,43)$. Platelet activation has been identified as a key factor in ductal closure $(44,45)$ and a potential role of glutamate might be a hypothesis to consider in future research.

The two most important limitations of our study are the relative small sample size and that is based on a single amino acid determination instead of longitudinal samples collected throughout the first days of life. In the study of Fujita et al., the sample is much smaller (16 infants) than in our study but amino acid levels were determined at birth (arterial umbilical cord blood) and on the 2nd day of life (7). Interestingly, glutamate levels were not significantly diminished in the first sample. In addition, not only glutamate but also leucine, lysine, phenylalanine, valine, tryptophan, methionine, isoleucine, arginine, tyrosine and glycine concentrations were decreased in the PDA group on the 2 nd day of life (7). This was despite the fact that both the PDA and control groups received a similar regimen of amino acid supplementation. Of note, the amino acid mixture used by Fujita et al., had a much lower concentration of glutamate than the mixtures commonly used in Europe and America (7). However, the decrease in the levels of most amino acids, and not only glutamate, may suggest a general increase in the demand for amino acids in extremely preterm infants with PDA.

To the best of our knowledge, few other studies have evaluated the association between PDA and amino acid concentrations within the 1st days of life. Ryckman et al. analyzed amino acid concentrations in dried blood spot samples taken on day 1-3 in a cohort of 689 preterm infants $(\mathrm{GA}<37$ weeks) of which 133 had PDA. The levels of glutamate were not affected but leucine, methionine, phenylalanine, and valine concentrations were higher in infants with PDA as compared with those without. Nevertheless, the differences did not reach the limit of statistical significance set by the authors to correct for multiple testing $\left(P<5 \times 10^{-5}\right)$. The authors reported similar results when the analysis was limited to the infants with GA below 32 weeks. Ryckman et al. also tested the ex vivo response of mouse DA to leucine, methionine, phenylalanine, and valine and observed that the amino acids failed to produce a significant change in ductal tone. Unfortunately, the ductal response to glutamate was not investigated. Very recently, Oltman et al. reported in a cohort of 34,969 infants with GA $<37$ weeks $(1,924$ infants with $\mathrm{GA}<32$ weeks) that increased risk for morbidity (including PDA) or mortality was associated with increased concentrations of glycine and proline, as well as decreased concentrations of ornithine in dried blood spot samples taken during the 1st week of life (46). Finally, Bardanzellu et al. showed decreased tryptophan urinary levels (samples collected $<12 \mathrm{~h}$ of life) in preterm infants with PDA (47). Therefore, the association between PDA and amino acid concentrations varies greatly between studies, making difficult to draw conclusions about the specific role of a particular amino acid in DA biology and pathobiology.

In summary, our study not only does not confirm the previous findings of low glutamate levels in preterm infants with PDA, but we have even found elevated glutamate concentrations associated with PDA. However, association does not mean causality. Despite the high statistical significance, the difference in glutamate levels may lack clinical significance or may be an epiphenomenon associated with the particular clinical condition of infants with PDA.

\section{DATA AVAILABILITY STATEMENT}

The raw data supporting the conclusions of this article will be made available by the authors, without undue reservation.

\section{ETHICS STATEMENT}

The studies involving human participants were reviewed and approved by Ethics Committees from Maastricht University Medical Center (Maastricht, The Netherlands), Hospital Universitario Materno-Infantil de Canarias (Las Palmas de Gran Canaria, Spain), and Carlo Poma Hospital (Mantova, Italy). Written informed consent to participate in this study was provided by the participants' legal guardian/next of kin.

\section{AUTHOR CONTRIBUTIONS}

MH, MB-L, GC, GG-L, GR, and PB-S collected data for the study, contributed to interpretation of results, and reviewed 
and revised the manuscript. JB performed the amino acid analysis, contributed to interpretation of results, and reviewed and revised the manuscript. RM contributed to the design of the study, collected data and supervised data collection, performed the statistical analysis, contributed to interpretation of results, and reviewed and revised the manuscript. EV conceptualized the study, supervised data collection and statistical analysis, contributed to interpretation of results, and drafted the manuscript. All authors contributed to the article and approved the submitted version.

\section{REFERENCES}

1. Hundscheid T, Onland W, Van Overmeire B, Dijk P, van Kaam AH, Dijkman KP, et al. Early treatment versus expectative management of patent ductus arteriosus in preterm infants: a multicentre, randomised, non-inferiority trial in Europe (BeNeDuctus trial). BMC Pediatr. (2018) 18:262. doi: 10.1186/s12887-018-1215-7

2. Reese J, Laughon MM. The patent ductus arteriosus problem: infants who still need treatment. J Pediatr. (2015) 167:954-6. doi: 10.1016/j.jpeds.2015.08.023

3. Sallmon H, Koehne P, Hansmann G. Recent advances in the treatment of preterm newborn infants with patent ductus arteriosus. Clin Perinatol. (2016) 43:113-29. doi: 10.1016/j.clp.2015.11.008

4. Villamor E, Moreno L, Mohammed R, Pérez-Vizcaíno F, Cogolludo A. Reactive oxygen species as mediators of oxygen signaling during fetalto-neonatal circulatory transition. Free Radic Biol Med. (2019) 142:8296. doi: 10.1016/j.freeradbiomed.2019.04.008

5. Stoller JZ, DeMauro SB, Dagle JM, Reese J. Current perspectives on pathobiology of the ductus arteriosus. J Clin Exp Cardiol. (2012) 8:S8001. doi: 10.4172/2155-9880.S8-001

6. Gillam-Krakauer M, Reese J. Diagnosis and management of patent ductus arteriosus. Neoreviews. (2018) 19:e394-402. doi: 10.1542/neo.19-7-e394

7. Fujita S, Yokoyama U, Ishiwata R, Aoki R, Nagao K, Masukawa D, et al. Glutamate promotes contraction of the rat ductus arteriosus. Circ J. (2016) 80:2388-96. doi: 10.1253/circj.CJ-16-0649

8. Shelton EL, Ector G, Galindo CL, Hooper CW, Brown N, Wilkerson I, et al. Transcriptional profiling reveals ductus arteriosus-specific genes that regulate vascular tone. Physiol Genomics. (2014) 46:457-66. doi: 10.1152/physiolgenomics.00171.2013

9. Hsieh Y-T, Liu NM, Ohmori E, Yokota T, Kajimura I, Akaike T, et al. Transcription profiles of the ductus arteriosus in Brown-Norway rats with irregular elastic fiber formation. Circ J. (2014) 78:122433. doi: 10.1253/circj.CJ-13-1029

10. Moonen RM, Huizing MJ, Cavallaro G, González-Luis GE, Bas-Suárez P, Bakker JA, et al. Plasma levels of dimethylarginines in preterm very low birth weight neonates: its relation with perinatal factors and short-term outcome. Int J Mol Sci. (2015) 16:19-39. doi: 10.3390/ijms16010019

11. Moonen RM, Reyes I, Cavallaro G, González-Luis G, Bakker JA, Villamor E. The T1405N carbamoyl phosphate synthetase polymorphism does not affect plasma arginine concentrations in preterm infants. PLOS ONE. (2010) 5:e10792. doi: 10.1371/journal.pone.0010792

12. Moonen RM, Cavallaro G, Huizing MJ, González-Luis GE, Mosca F, Villamor E. Association between the $\mathrm{p}$. Thr1406Asn polymorphism of the carbamoylphosphate synthetase 1 gene and necrotizing enterocolitis: a prospective multicenter study. Sci Rep. (2016) 6:36999. doi: 10.1038/srep36999

13. Bas-Suárez MP, González-Luis GE, Saavedra P, Villamor E. Platelet counts in the first seven days of life and patent ductus arteriosus in preterm very lowbirth-weight infants. Neonatology. (2014) 106:188-94. doi: 10.1159/000362432

14. Armstrong RA. When to use the Bonferroni correction. Ophthalmic Physiol Opt. (2014) 34:502-8. doi: 10.1111/opo.12131

15. Honkanen RA, Baruah S, Zimmerman MB, Khanna CL, Weaver YK, Narkiewicz J, et al. Vitreous amino acid concentrations in patients with glaucoma undergoing vitrectomy. Arch Ophthalmol. (2003) 121:1838. doi: $10.1001 /$ archopht.121.2.183

\section{FUNDING}

This work was partially supported by a grant from the Fundación Canaria del Colegio de Médicos de Las Palmas.

\section{SUPPLEMENTARY MATERIAL}

The Supplementary Material for this article can be found online at: https://www.frontiersin.org/articles/10.3389/fped. 2021.647018/full\#supplementary-material

16. Hu X, Guo F. Amino acid sensing in metabolic homeostasis and health. Endocr Rev. (2020) 42:56-76. doi: 10.1210/endrev/bnaa026

17. Celik IH, Demirel G, Canpolat FE, Dilmen U. Reduced plasma citrulline levels in low birth weight infants with necrotizing enterocolitis. J Clin Lab Anal. (2013) 27:328-32. doi: 10.1002/jcla.21607

18. Celik IH, Demirel G, Canpolat FE, Oguz SS, Erdeve O, Dilmen U. Citrulline levels in premature infants. Clin Chim Acta. (2011) 21:2007. doi: 10.1016/j.cca.2011.06.037

19. Canpolat FE, Yurdakök M, Yigit S, Korkmaz A, Tekinalp G. Blood L-arginine Levels in Early Respiratory Distress Syndrome. Pediatr Pulmonol. (2005) 40:511-4. doi: 10.1002/ppul.20326

20. Manal El, Sayed M, Sherif L, Said RN, El-Wakkad AS, Amira E-R, et al. Endothelin-1 and L-arginine in preterm infants with respiratory distress. Am J Perinatol. (2011) 28:129-36. doi: 10.1055/s-0030-1263295

21. Dumas SJ, Bru-Mercier G, Courboulin A, Quatredeniers M, Rücker-Martin C, Antigny F, et al. NMDA-type glutamate receptor activation promotes vascular remodeling and pulmonary arterial hypertension. Circulation. (2018) 137:2371-89. doi: 10.1161/CIRCULATIONAHA.117.029930

22. Brosnan JT, Brosnan ME. Glutamate: a truly functional amino acid. Amino Acids. (2013) 45:413-8. doi: 10.1007/s00726-012-1280-4

23. Riedijk MA, de Gast-Bakker D-AH, Wattimena JL, Van Goudoever JB. Splanchnic oxidation is the major metabolic fate of dietary glutamate in enterally fed preterm infants. Pediatr Res. (2007) 62:468-73. doi: 10.1203/PDR.0b013e31813cbeba

24. Yelamanchi SD, Jayaram S, Thomas JK, Gundimeda S, Khan AA, Singhal A, et al. A pathway map of glutamate metabolism. J Cell Commun Signal. (2016) 10:69-75. doi: 10.1007/s12079-015-0315-5

25. Terán Y, Ponce O, Betancourt L, Hernández L, Rada P. Amino acid profile of plasma and cerebrospinal fluid in preeclampsia. Pregnancy Hypertens. (2012) 2:416-22. doi: 10.1016/j.preghy.2012.05.001

26. Dessì A, Marincola FC, Fanos V. Metabolomics and the great obstetrical syndromes-GDM, PET, and IUGR. Best Pract Res Clin Obstet Gynaecol. (2015) 29:156-64. doi: 10.1016/j.bpobgyn.2014.04.023

27. Zhang Z, Bassam B, Thomas AG, Williams M, Liu J, Nance E, et al. Maternal inflammation leads to impaired glutamate homeostasis and up-regulation of glutamate carboxypeptidase II in activated microglia in the fetal/newborn rabbit brain. Neurobiol Dis. (2016) 94:116-28. doi: 10.1016/j.nbd.2016.06.010

28. Hirose T, Shimizu K, Ogura H, Tasaki O, Hamasaki T, Yamano S, et al. Altered balance of the aminogram in patients with sepsis-the relation to mortality. Clin Nutr. (2014) 33:179-82. doi: 10.1016/j.clnu.2013.11.017

29. Pregnolato S, Chakkarapani E, Isles AR, Luyt K. Glutamate transport and preterm brain injury. Front Physiol. (2019) 10:417. doi: 10.3389/fphys.2019.00417

30. Parfenova H, Fedinec A, Leffler CW. Ionotropic glutamate receptors in cerebral microvascular endothelium are functionally linked to heme oxygenase. J Cereb Blood Flow Metab. (2003) 23:190-7. doi: 10.1097/00004647-200302000-00006

31. Hinoi E, Takarada T, Ueshima T, Tsuchihashi Y, Yoneda Y. Glutamate signaling in peripheral tissues. Eur J Biochem. (2004) 271:1-13. doi: 10.1046/j.1432-1033.2003.03907.x

32. Hogan-Cann AD, Anderson CM. Physiological roles of nonneuronal NMDA receptors. Trends Pharmacol Sci. (2016) 37:750-67. doi: 10.1016/j.tips.2016.05.012 
33. Nguyen-Duong H. Effects of glutamate and zinc ions on the contractility of vascular smooth muscle preparations. J Elementol. (2010) 15:559-72. doi: 10.5601/jelem.2010.15.3.559-572

34. Sun H, Swaim A, Herrera JE, Becker D, Becker L, Srivastava $\mathrm{K}$, et al. Platelet kainate receptor signaling promotes thrombosis by stimulating cyclooxygenase activation. Circ Res. (2009) 105:595-603. doi: 10.1161/CIRCRESAHA.109. 198861

35. Kalev-Zylinska ML, Hearn JI, Makhro A, Bogdanova A. N-methyl-Daspartate receptors in hematopoietic cells: what have we learned? Front Physiol. (2020) 11:577. doi: 10.3389/fphys.2020.00577

36. LeMaistre JL, Sanders SA, Stobart MJ, Lu L, Knox JD, Anderson HD, et al. Coactivation of NMDA receptors by glutamate and D-serine induces dilation of isolated middle cerebral arteries. J Cereb Blood Flow Metab. (2012) 32:537-47. doi: 10.1038/jcbfm.2011.161

37. Du J, Li X-H, Li Y-J. Glutamate in peripheral organs: biology and pharmacology. Eur J Pharmacol. (2016) 784:428. doi: 10.1016/j.ejphar.2016.05.009

38. Jiang H, Holm J, Vidlund M, Vanky F, Friberg Ö, Yang Y, et al. The impact of glutamate infusion on postoperative NT-proBNP in patients undergoing coronary artery bypass surgery: a randomized study. J Transl Med. (2020) 18:1-11. doi: 10.1186/s12967-020-02351-7

39. Meng W, Tobin JR, Busija DW. Glutamate-induced cerebral vasodilation is mediated by nitric oxide through N-methyl-D-aspartate receptors. Stroke. (1995) 26:857-63. doi: 10.1161/01.STR.26.5.857

40. Fiumana E, Parfenova H, Jaggar JH, Leffler CW. Carbon monoxide mediates vasodilator effects of glutamate in isolated pressurized cerebral arterioles of newborn pigs. Am J Physiol. (2003) 284:H1073-9. doi: 10.1152/ajpheart.00881.2002

41. Koneru P, Leffler CW. Role of cGMP in carbon monoxideinduced cerebral vasodilation in piglets. Am J Physiol. (2004) 286:H304-9. doi: 10.1152/ajpheart.00810.2003
42. Hall CN, Reynell C, Gesslein B, Hamilton NB, Mishra A, Sutherland BA, et al. Capillary pericytes regulate cerebral blood flow in health and disease. Nature. (2014) 508:55-60. doi: 10.1038/nature13165

43. Morrell CN, Sun H, Ikeda M, Beique J-C, Swaim AM, Mason E, et al. Glutamate mediates platelet activation through the AMPA receptor. J Exp Med. (2008) 205:575-84. doi: 10.1084/jem.20071474

44. Echtler K, Stark K, Lorenz M, Kerstan S, Walch A, Jennen L, et al. Platelets contribute to postnatal occlusion of the ductus arteriosus. Nat Med. (2010) 16:75-82. doi: 10.1038/nm.2060

45. Simon SR, van Zogchel L, Bas-Suárez MP, Cavallaro G, Clyman RI, Villamor E. Platelet counts and patent ductus arteriosus in preterm infants: a systematic review and meta-analysis. Neonatology. (2015) 108:14351. doi: 10.1159/000431281

46. Oltman SP, Rogers EE, Baer RJ, Jasper EA, Anderson JG, Steurer MA, et al. Newborn metabolic vulnerability profile identifies preterm infants at risk for mortality and morbidity. Pediatr Res. (2020):110. doi: 10.1038/s41390-020-01148-0. [Epub ahead of print].

47. Bardanzellu F, Piras C, Atzei A, Neroni P, Fanos V. Early urinary metabolomics in patent ductus arteriosus anticipates the fate: preliminary data. Front Pediatrics. (2020) 8:872. doi: 10.3389/fped.2020.613749

Conflict of Interest: The authors declare that the research was conducted in the absence of any commercial or financial relationships that could be construed as a potential conflict of interest.

Copyright (C) 2021 Huizing, Borges-Luján, Cavallaro, González-Luis, Raffaeli, BasSuárez, Bakker, Moonen and Villamor. This is an open-access article distributed under the terms of the Creative Commons Attribution License (CC BY). The use, distribution or reproduction in other forums is permitted, provided the original author(s) and the copyright owner(s) are credited and that the original publication in this journal is cited, in accordance with accepted academic practice. No use, distribution or reproduction is permitted which does not comply with these terms. 